Article

\title{
Start-Up Current Spike Mitigation of High-Power Laser Diode Driving Controller for Vehicle Headlamp Applications
}

\author{
Kai-Jun Pai ${ }^{1, *(\mathbb{D})}$, Lin-De Qin ${ }^{2}$, Chang-Hua Lin ${ }^{3}$ and Sheng-Yi Tang ${ }^{4}$ \\ 1 Department of Electrical Engineering, Ming Chi University of Technology, New Taipei City 24301, Taiwan \\ 2 Department of Electrical Engineering, Tungnan University, New Taipei City 22202, Taiwan; \\ show9051649@gmail.com \\ 3 Department of Electrical Engineering, National Taiwan University of Science and Technology, \\ Taipei City 10607, Taiwan; link@mail.ntust.edu.tw \\ 4 Department of Power Mechanical Engineering, National Formosa University, Huwei Town, \\ Yunlin County 63201, Taiwan; arthurta@nfu.edu.tw \\ * Correspondence: carypai@mail.mcut.edu.tw; Tel.: +886-2-2908-9899 (ext. 4849)
}

Received: 26 July 2018; Accepted: 29 August 2018; Published: 1 September 2018

check for updates

Featured Application: Vehicle headlamp and laser diode driving and control.

\begin{abstract}
A high-power laser diode driving controller (HPLDDC), which incorporates the power converter with the feedback controller, was developed and implemented in this paper. The synchronous buck-boost converter (SBBC) was the topology of the power converter; the SBBC could be operated in step-up or step-down mode in accordance with variable on-board battery voltage inputs into the HPLDDC. Moreover, the feedback controllers were equipped with a current-loop controller (CLC) and a voltage-loop controller (VLC); the VLC was employed to regulate the SBBC output voltage to drive and start-up the high-power laser diode (HPLD). The CLC was used to regulate the SBBC output current to supply a constant-current driving the HPLDs. During the start-up transient phase, when the SBBC output mode is changed from the constant-voltage to the constant-current, a start-up current spike occurs that can destroy the semiconductor material of the laser diode. However, few studies have discussed methods of coping with this problem. Therefore, this study proposed a proportional-integral associating proportional (PIAP) control technology, which can be applied to the CLC for the start-up current spike mitigation. Complete designs and analyses are presented in this paper. Simulations and experiments validate that the PIAP control method is effectual to solve the start-up current spike.
\end{abstract}

Keywords: high-power laser diode; synchronous buck-boost converter; proportional-integral associating proportional

\section{Introduction}

As semiconductor technology continues to develop and innovate, the uses of electronic devices and elements in the on-board parts of vehicles or electric cars are progressively increasing. Twin headlamps in the front end of vehicles, including the blink lights, low beam lights, and high beam lights, are applied to cope with different traffic circumstances. In vehicle headlamps, incandescent halogen lamps have been replaced with optoelectronic semiconductors (OPSs) in a new generation of cars, due to their benefits such as direct-current (DC) driving, high brightness, high efficiency of power conversion, and outstanding color rendering [1-6]. In addition, when motor vehicles are driven in road tunnels or on roadways in the night, the headlamp irradiation ranges can be expanded using high beam 
lights, the brightness of which settles on metal halide high-intensity discharge (HID) lamps. However, several negative characteristics of HID lamps should be contemplated, including alternating-current (AC) power driving, AC high-voltage start-up, and negative resistance characteristic; thus, electronic ballasts can be used to stabilize the brightness and driving current of HID lamps [7-9].

The abbreviation, laser, is an acronym for light amplification by stimulated emission of radiation. According to laser oscillator configurations, laser devices can be classified based on the various materials used for construction, such as solid-state laser, gas laser, semiconductor laser, and fiber laser. Figure 1a is a simple model of the semiconductor laser, whose active layer is embedded in between the p-type and n-type materials. The p-type Gallium Nitride ( $\mathrm{p}-\mathrm{GaN}$ ) can be a positive electrode, and the n-type Gallium Nitride ( $n-G a N)$ contact can be a negative electrode. When the laser diode (LD) is excited, the active layer can emit laser beams, which can be amplified using the mirror surfaces to emit laser beams [10]. When voltage from a power source is applied to the positive-negative electrode and the laser diode operates in the forward bias, the electrons are injected into the active layer from the n-type semiconductor; the wide band gap of the heterojunction can limit the amount of electron combinations in the active layer, and, through this carrier confinement, the population inversion probabilities can be substantially increased to promote high-intensity light emission [11], as shown in Figure $1 \mathrm{~b}$. In addition, the semiconductor laser possesses several exceptional characteristics, including monochromaticity, high directionality, high coherence, and high energy density. Thus, motor vehicle manufacturers have started to develop the high beam light of high brightness based on the high-power laser diode (HPLD).

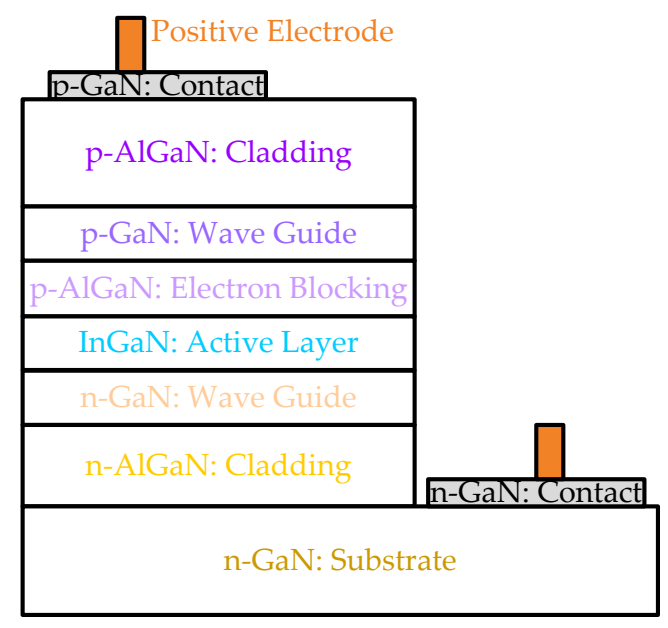

(a)

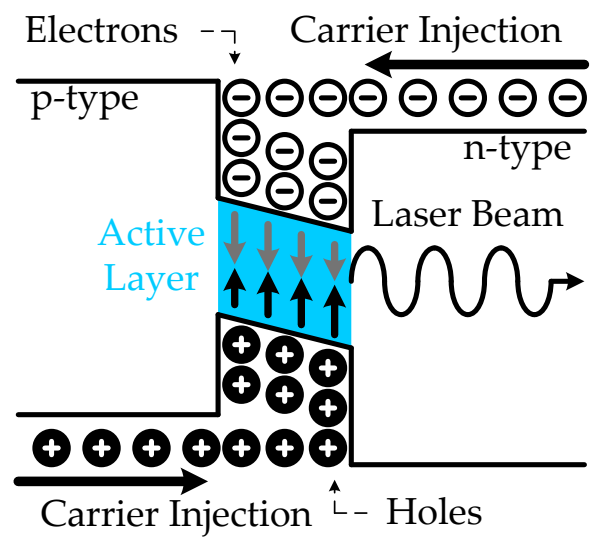

(b)

Figure 1. Laser diode configuration and heterojunction: (a) Semiconductor configuration; (b) recombination of electron-hole pair at the heterojunction.

In this study, the HPLD of InGaN-based blue beam was used as the illuminant sources for vehicle headlamps. Due to the optical output power (OOP) of HPLD being directly proportional to its forward operating current [12], the HPLDs must be driven by a constant-current (CC). Therefore, the design of high-power laser diode driving controller (HPLDDC) requires a current-loop controller (CLC) and a voltage-loop controller (VLC) to manipulate the HPLDDC, achieving the constant-current output mode (CCOM) and constant-voltage output mode (CVOM), and the CLC and VLC can apply the proportional-integral (PI) control to accomplish the low steady-state error and system stable requirement. The PI control has excellent behavior in the low steady-state error; however, the tardy response speed of PI control can result in the current spike problem and the long settling time during the HPLDDC start-up transient phase. Therefore, studies [13-15] have proposed the use of dual control loops, including the proportional (P) control and PI control, in which the P control can promote 
transient responses, and the dual control loops combined a P control loop with a PI control loop to reduce steady-state errors; thus, the system can address the requirements of transient responses and steady-state stability. However, the implementations of dual control loops with P and PI controls in the HPLDDC are too complex. Therefore, this study employed a control method, proportional-integral, associating proportional (PIAP) control, to depress the start-up current spikes.

An HPLDDC was implemented and developed in this study to drive blue beam HPLDs as the illuminant source for motor vehicle headlamps. Because the on-bard battery was used as the HPLDDC's input power and the battery voltage varied during charging or discharging, a synchronous buck-boost converter (SBBC) was applied as the power converter of HPLDDC. In addition, SBBC's CCOM or CVOM operation could be implemented through the CLC or VLC manipulation. During the HPLDDC start-up transient phase, when the HPLDDC changed its output mode from the CVOM to CCOM, the CLC adopting the PIAP control was effectual for the start-up current spike depressing. Six sections are presented in this paper. SBBC principles and analyses are presented in Section 2. The PIAP control method to solve the start-up current problem is explained and analyzed in Section 3. Section 4 includes design considerations, analyses, and simulations for the HPLDDC current loop. In Section 5, experimental waveforms can confirm that the PIAP control is efficacious. Section 6 is this study's conclusions.

\section{Power Converter Principle}

The HPLDDC system configuration is depicted in Figure 2, including the CVOM and CCOM controllers, a DC-DC convertor, and safety standard components. The on-board battery supplies a DC-power to the HPLDDC inlet; the HPLDDC outlet connects three HPLDs in series. To protect the SBBC, CVOM, and CCOM controllers, the SBBC input side must place safety standard components because voltage impulses and spikes or EMI/EMC noises from the battery power bus can be filtered out. In addition, the DC-DC converter topology is the SBBC; an SBBC circuit is shown in Figure 3; this circuit composition includes an output capacitor, $C_{0}$, power switches, $Q_{1}-Q_{4}$, and an inductor, $L_{1}$. Principles and analyses in the buck and boost modes are discussed in the following.

High-Power Laser Diode Driving Controller

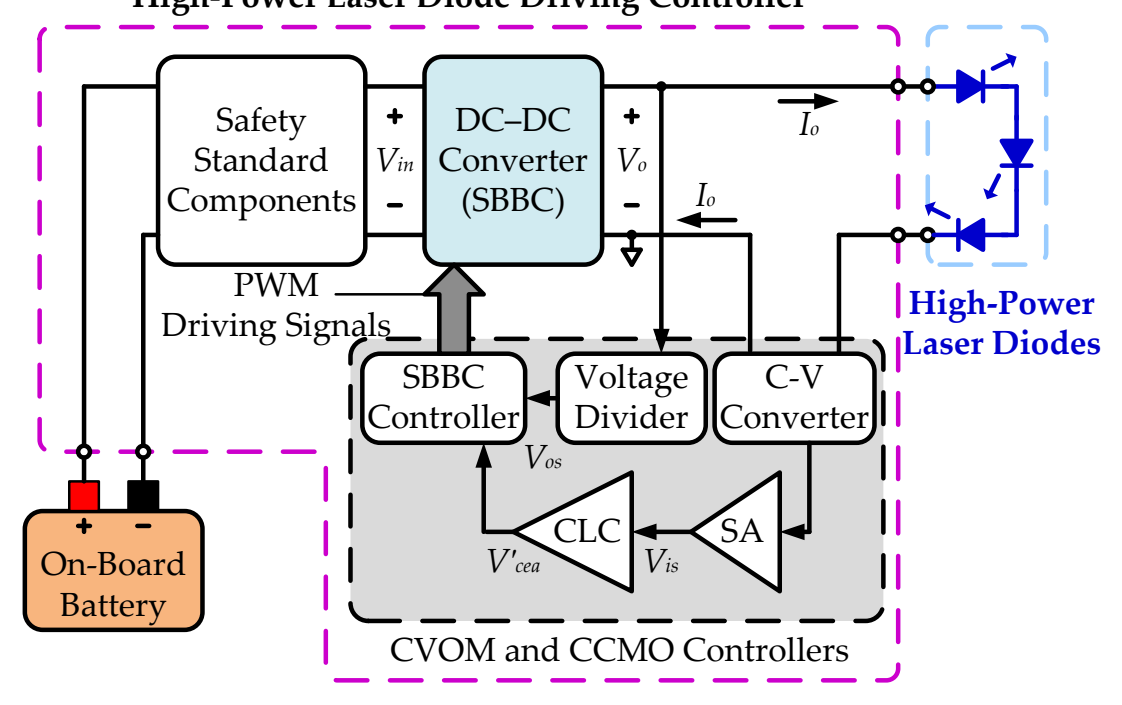

Figure 2. High-power laser diode driving controller (HPLDDC) system configuration. 


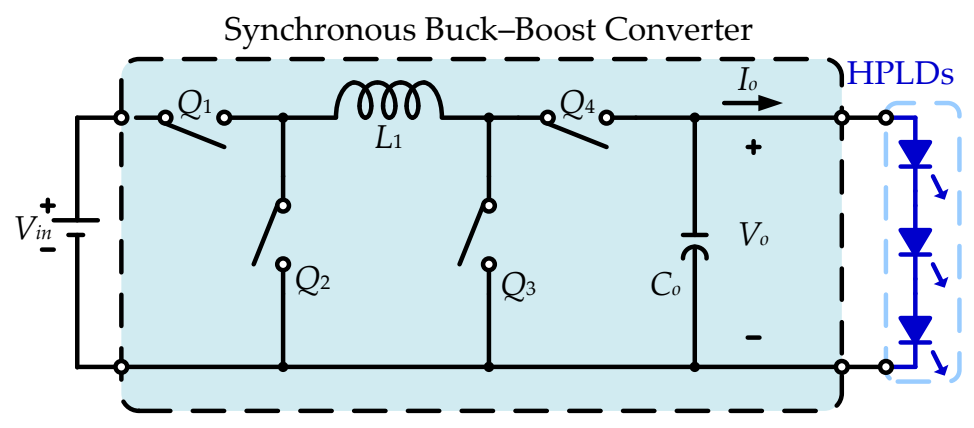

Figure 3. Synchronous buck-boost converter.

\subsection{Buck Mode Principle}

In the buck operation, power switches, $Q_{1}-Q_{4}$, (Figure 3) are replaced with power metal-oxidesemiconductor field-effect transistors (MOSFETs); the synchronous buck circuit with the operating timing is presented in Figure 4 . In Figure $4 \mathrm{a}, v_{g s 1}-v_{g s 4}$ are the MOSFET gate-to-source pulse width modulation (PWM) driving signals, and $i_{L}$ represents the inductor current. When the SBBC input voltage, $V_{i n}$, is greater than the HPLDDC output voltage, $V_{o}\left(V_{i n}>V_{o}\right), v_{g s}$ is at the high-voltage level, and, consequently, the MOSFET $Q_{4}$ is always turned on; $v_{g s 3}$ is always at the low-voltage level to turn off the MOSFET $Q_{3}$. The time intervals, $t_{k 0}-t_{k 1}$ and $t_{k 2}-t_{k 3}$, are dead times that can prevent MOSFETs $Q_{1}$ and $Q_{2}$ from concurrently turning on and becoming a short-circuit. $v_{g s 2}$ is changed to the high-voltage level during the time interval, $t_{k 1}-t_{k 2}$, thereby decreasing $i_{L}$. Figure $4 \mathrm{~b}$ presents the operating circuit during the time interval, $t_{k 0}-t_{k 2}$.

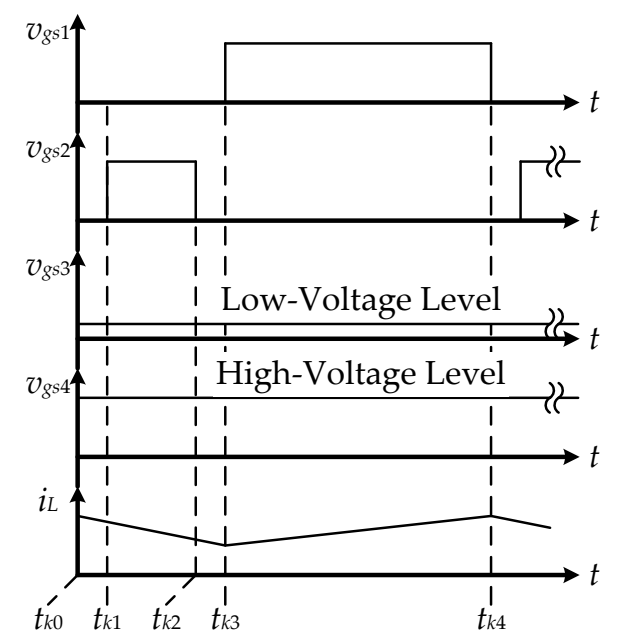

(a)

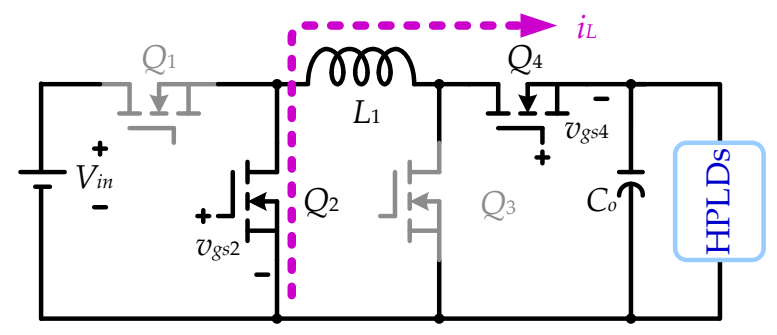

(b)

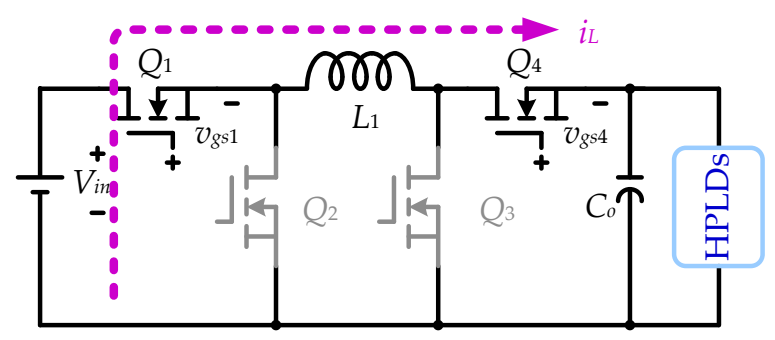

(c)

Figure 4. Buck mode principle: (a) $v_{g s 1}-v_{g s 4}$ and $i_{L}$ timing charts; (b) operating circuit in $t_{k 1}-t_{k 2}$; and (c) operating circuit in $t_{k 3}-t_{k 4}$.

When $i_{L}$ is lower than the current command inside the SBBC controller at $t_{k 2}, v_{g_{s} 2}$ is changed to the low-voltage level, thus, turning off $Q_{2}$, and $v_{\text {gs } 1}$ is changed to the high-voltage level at $t_{k 3}$, thus, increasing $i_{L}$. The operating circuit during the time interval, $t_{k 3}-t_{k 4}$, is depicted in Figure $4 \mathrm{c}$. When $i_{L}$ is greater than the current command inside the SBBC controller at $t_{k 4}, v_{g s 1}$ is changed to the low-voltage level, thus, turning off $Q_{1}$. 


\subsection{Boost Mode Principle}

Figure 5 illustrates the synchronous boost circuit and the timing chart. When $V_{\text {in }}$ is lower than $V_{o}\left(V_{\text {in }}<V_{o}\right)$ throughout the operation, $v_{g s 1}$ is at the high-voltage level to turn on $Q_{1}$, and $v_{g s 2}$ is at the low-voltage level to turn off $Q_{2}$. Both the time intervals, $t_{t 0}-t_{t 1}$ and $t_{t 2}-t_{t 3}$, are dead times that can prevent $Q_{3}$ and $Q_{4}$ from concurrently turning on and causing the short-circuit. $v_{g s 3}$ is changed to the high-voltage level during the time interval, $t_{t 1}-t_{t 2}$, thus, increasing $i_{L}$; the operating circuit in the time interval, $t_{t 1}-t_{t 2}$, is depicted in Figure $5 \mathrm{~b}$. At $t_{t 2}$, because $i_{L}$ is greater than the current command inside the SBBC controller, $v_{83}$ is changed to the low-voltage level, thus, turning off $Q_{3}$. In the time interval, $t_{t 3}-t_{t 4}, v_{g 4}$ is at the high-voltage level and $Q_{4}$ is turned on, hence, decreasing $i_{L}$; the operating circuit during $t_{t 3}-t_{t 4}$ is depicted in Figure $5 \mathrm{c}$. When $i_{L}$ is lower than the current command inside the SBBC controller at time, $t_{t 4}, v_{g s}$ is changed to the low-voltage level, thus, turning off $Q_{4}$.

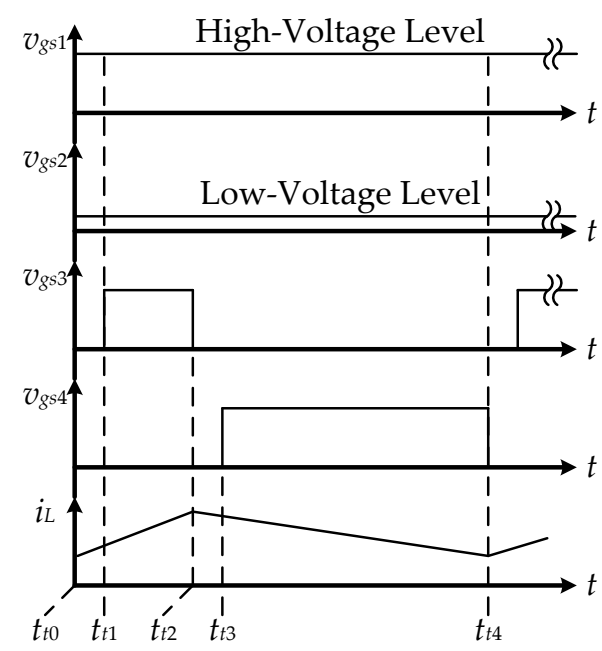

(a)

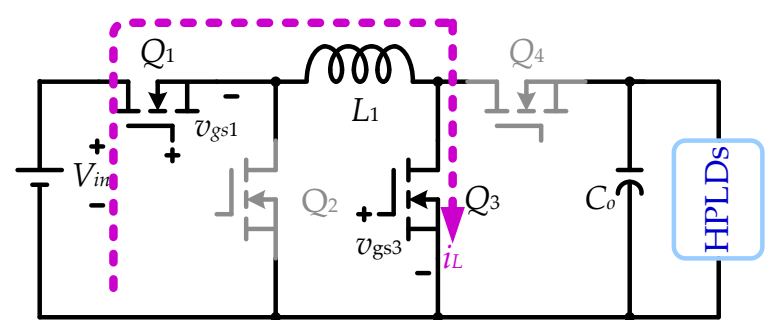

(b)

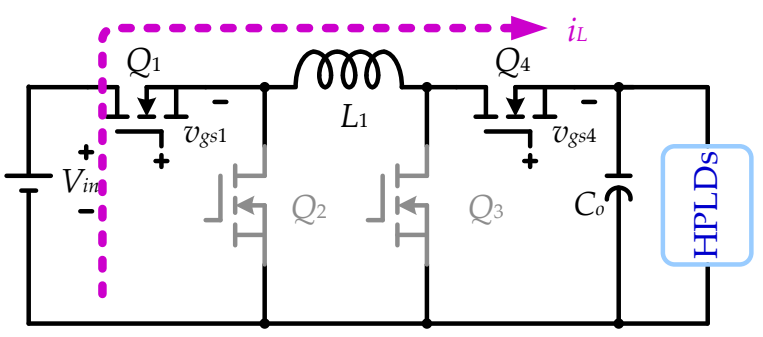

(c)

Figure 5. Boost mode principle: (a) $v_{g s 1}-v_{g s 4}$ and $i_{L}$ timing charts; (b) operating circuit in $t_{t 1}-t_{t 2}$; (c) operating circuit in $t_{t 3}-t_{t 4}$.

\subsection{Designs of Output Capacitor and Inductor}

Because the SBBC was the topology of the power converter, which can implement the buck or boost mode, the output capacitor and inductor should be computed to address the practical circuit application. The calculating formulas and explanations are in the following sections.

\subsubsection{SBBC Inductor for Buck Mode}

In accordance with the study [14], the inductor for the SBBC's buck mode operation can be estimated as follows:

$$
L_{b k}=D_{b k}\left(V_{i n(\max )}-V_{\mathrm{o}(\min )}\right) /\left(2 f_{s} \Delta i_{L}\right) .
$$

The notation, $L_{1}$, (Figure 3) can be replaced with $L_{b k}$. $\Delta i_{L}$ is the inductor peak current that can be estimated using the $\beta I_{0}, \beta$ is the percent from the peak-to-peak inductor current, and $I_{0}$ is the HPLDDC output current. $D_{b k}$ is the duty cycle of the buck mode that can be estimated using the $V_{o(\min )} / V_{i n(\max )}$, $V_{o(\min )}$ is the HPLDDC minimum output voltage, and $V_{o(\max )}$ is the HPLDDC maximum output voltage. $f_{s}$ is the switching frequency of $Q_{1}-Q_{4}$. Substitution of $\Delta i_{L}=\beta I_{o}$ and $D_{b k}=V_{o(\min )} / V_{\text {in(max) }}$ into (1) can rewrite the equation as follows:

$$
L_{b k}=V_{o(\min )}\left(V_{i n(\max )}-V_{o(\min )}\right) /\left(2 V_{i n(\max )} f_{s} I_{o} \beta\right) .
$$




\subsubsection{SBBC Inductor for Boost Mode}

In accordance with the study [16], the inductor for the SBBC's boost mode operation can be estimated as follows:

$$
L_{b t}=V_{i n(\min )} D_{b t} /\left(2 f_{s} \Delta i_{L}\right)
$$

$L_{1}$ can be replaced with $L_{b t}, D_{b t}$ is the duty cycle of the boost mode that can be estimated using $\left(V_{o(\max )}-V_{\text {in (min })}\right) / V_{o(\max )} . V_{\text {in (min) }}$ is the HPLDDC minimum input voltage. Substitution of $\Delta i_{L}=\beta I_{o}$ and $D_{b t}=\left(V_{o(\max )}-V_{i n(\min )}\right) / V_{o(\max )}$ into Equation (3) can rewrite the equation as follows:

$$
L_{b t}=V_{i n(\min )}\left(V_{o(\max )}-V_{i n(\min )}\right) /\left(2 f_{s} V_{o(\max )} I_{o} \beta\right) .
$$

\subsubsection{SBBC Output Capacitor}

In accordance with the study [16], the SBBC output capacitor (Figure 3) can be estimated as follows:

$$
C_{o}=D V_{o} /\left(2 \Delta v_{o} f_{s} R_{o}\right),
$$

where $D$ represents the duty cycle from $D_{b k}$ or $D_{b t} . \Delta v_{\mathrm{o}}$ is the HPLDDC output ripple voltage that can be estimated using $\left\langle V_{o(\min )}\right.$, and the ripple voltage peak can be defined by a percentage, $\alpha . R_{o}$ is the output equivalent resistance at the HPLDDC output side.

In addition, an effective series resistance (ESR) parasitizes on $C_{o}$ that can be expressed as follows [17]:

$$
E S R \leq \Delta v_{0} / I_{\text {in }(\text { peck })}
$$

where $I_{\text {in(peak) }}$ is the peak value of the HPLDDC input current. According to $I_{o} / I_{\text {in }}=1 / D_{b k}, I_{\text {in(peak })}$ can be estimated as $I_{0} D_{b k}(1+\beta)$.

\section{- $\quad$ SBBC Output Capacitor for Buck Mode}

For the buck mode, the notation $C_{o}$ in Equation (5) can be replaced with $C_{o b k}$. Substitution of $C_{o}=C_{o b k}, V_{o}=V_{o(\text { min })}, R_{o}=V_{o(\text { min })} / I_{o}, D=D_{b k}=V_{o(\text { min })} / V_{\text {in(max) }}$, and $\Delta v_{o}=\alpha V_{o(\text { min })}$ into Equation (5) obtains the output capacitor of the buck mode operation as follows:

$$
C_{o b k}=I_{o} /\left(2 V_{i n(\max )} \alpha f_{s}\right) .
$$

$E S R$ in Equation (6) is replaced with $E S R_{b k}$. Substitution of $\Delta v_{o}=\alpha V_{o(\min )}$ and $D_{b k}=V_{o(\min )} / V_{i n(\max )}$ into Equation (6) can rewrite the equation as follows:

$$
E S R_{b k} \leq \alpha V_{i n(\max )} /\left[I_{o}(1+\beta)\right]
$$

- $\quad$ SBBC Output Capacitor for Boost Mode

For the boost mode, $C_{o}$ can be replaced with $C_{o b t}$. Substitution of $C_{o}=C_{o b t}, V_{o}=V_{o(\max )}, D=D_{b t}=$ $\left(V_{o(\max )}-V_{o(\min )}\right) / V_{o(\max )}, \Delta v_{o}=\alpha V_{o(\max )}$, and $R_{o}=V_{o(\max )} / I_{o}$ into Equation (5) can obtain the output capacitor of the boost mode as follows:

$$
C_{o b t}=I_{o}\left(V_{o(\max )}-V_{i n(\min )}\right) /\left(2 \alpha V_{o(\max )}^{2} f_{s}\right) .
$$

$E S R$ is replaced with $E S R_{b t}$. Substitution of $\Delta v_{o}=\alpha V_{o(\min )}$ and $D_{b t}=\left(V_{o(\max )}-V_{\text {in }(\min )}\right) / V_{o(\max )}$ into (6) can rewrite the equation as follows:

$$
E S R_{b t} \leq \alpha V_{i n(\min )} /\left[I_{o}(1+\beta)\right]
$$




\section{HPLDDC Control Loop}

Figure 6 depicts the ideal voltage-current characteristic of LD; $V_{L D F}$ is the forward voltage of LD and a slight current (approximating to no current) flows if the LD driving voltage is lower than $V_{L D F}$. Without any driving devices to regulate the LD driving current, if the LD driving voltage is higher than $V_{L D F}$, more current is indispensable to drive the LD strengthening the laser beams, and the driving current can be increased exponentially. Because the constant OOP originates from a stable LD driving current, the LD can be driven by a CC output power supply, or regulated by a CC sink. Several control methods for the LD driving are discussed in the following section.

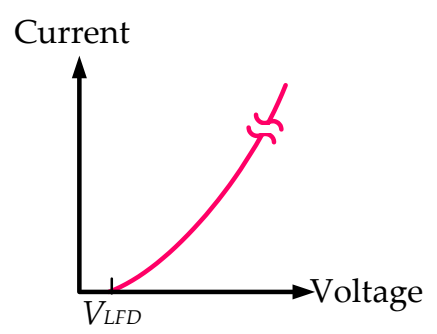

Figure 6. Laser diode (LD) voltage-current characteristic.

\subsection{Constant-Current Sink Control}

The optoelectronic semiconductor (OPS) including the light-emitting diode (LED), the organic light-emitting diode (OLED), and the LD, should be driven by a CC to obtain a constant OOP or luminance. Figure 7 presents a familiar OPS control circuit that includes the lighting driver, OPSs, and the current regulator (CR). To control the constant driving current in OPSs, a CR comprising an operational amplifier (OPA), a transistor, and a current-voltage (C-V) converter, is the critical circuit because the CR can be considered as a current sink; when the OPS operates in the forward bias, the OPS driving current $I_{f}$ sinks into the transistor, and then $I_{f}$ can be converted by the $\mathrm{C}-\mathrm{V}$ converter becoming a voltage $V_{I f}$; therefore, the transistor can be considered as a variable resistance for adjusting the $I_{f}$ because the OPA compares the $V_{I f}$ with a CC command to control the transistor's operating region $[18,19]$. However, the $C R$ is unable to address less steady-state errors and sufficient phase margins. Moreover, the lighting driver is a constant-voltage (CV) power source, and although the CC can be achieved using the CR; however, the transistor's equivalent resistance would cause the power loss and heating. Therefore, the CR is unsuitable for the high-power OPS control.

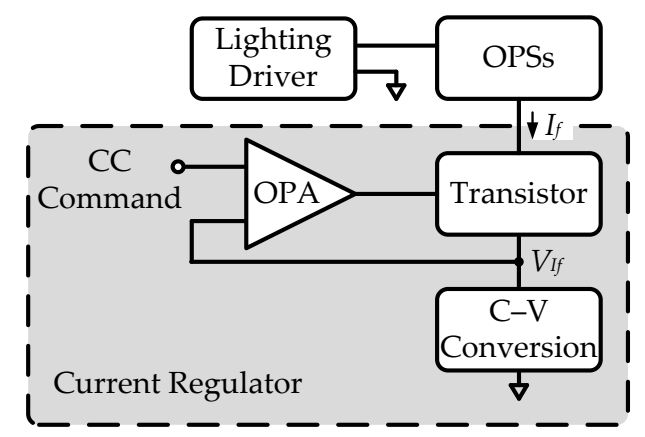

Figure 7. Constant-current (CC) sink control of optoelectronic semiconductor (OPS).

\subsection{Constant-Current Source Driving and CLC Using PI Control}

To supply a CV or CC DC-power to drive HPLDs, CVOM and CCOM controllers play a critical role in dominating HPLDDC operations. In Figure 2, CVOM and CCOM controllers comprise a SBBC controller, a C-V converter, a voltage divider, a signal amplifier (SA), and a CLC. As shown in Figure 8, 
to accomplish the HPLDDC's CVOM, the voltage divider detects $V_{o}$ to output a voltage $V_{o s}$, and then the VLC of SBBC controller can obey $V_{o s}$ to produce an error voltage to manipulate the PWM module. Therefore, the HPLDDC can be controlled in the CVOM to supply the adequate and stable forward voltage driving HPLDs. In addition, in the HPLDDC's CCOM, the HPLD driving current can be detected by the $\mathrm{C}-\mathrm{V}$ converter to become a voltage signal, and then the SA can amplify this voltage signal becoming a current detection signal $V_{i s}$. According to the $V_{i s}$ variation, an error voltage $V_{c e a}^{\prime}$ can be produced by the CLC to manipulate the SBBC controller accomplishing the HPLDDC CCOM.

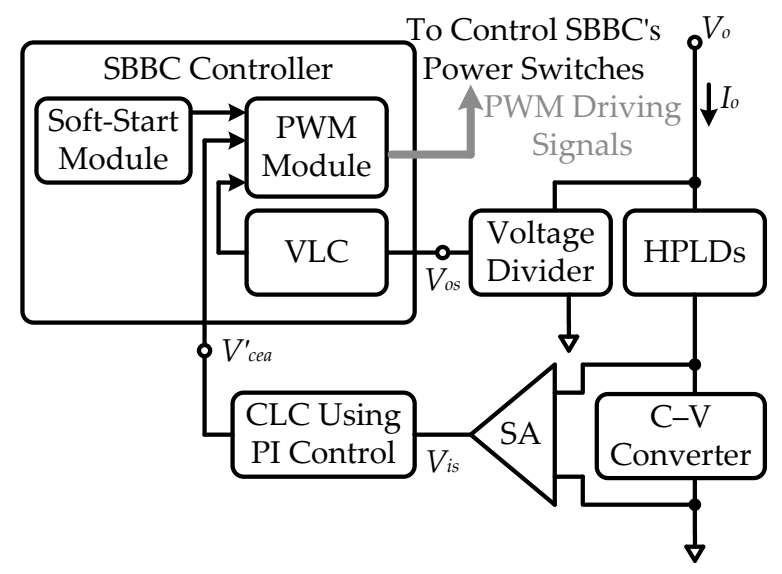

Figure 8. HPLDDC's voltage-loop controller (VLC) and current-loop controller (CLC) control loops.

Both start-up voltage and current spikes are pernicious to the HPLD's semiconductor material. The start-up voltage spike can be solved using the soft-start module (Figure 8). Moreover, the integral action of the PI control causes the start-up current spike; thus, when the SBBC output mode is changed from CVOM to CCOM, the HPLD driving current should avoid the start-up current spike occurrence.

\subsection{Constant-Current Source Driving and CLC Using PIAP Control}

A circuit configuration diagram of CLC using the PIAP control is depicted in Figure 9. In Figure 9b, during Phase I, the HPLDDC is dominated by the VLC and the soft-start module of the SBBC controller, and then $V_{o}$ can slowly increase to avoid the voltage overshoot occurrence. When the $I_{o}$ increase has reached a current value of $I_{1}$, a switch, st, (Figure 9a) connects to the position, $\mathrm{s}_{1}$; thus, the CLC can implement P control during Phase II (Figure 9b), hence, the response speed of CLC can be promoted to mitigate the start-up current spike. In Phase III, $I_{0}$ has reached the target CC $I_{c c}$, the st connects to the position, $\mathrm{s}_{2}$, and then the CLC uses the PI control to regulate the HPLD driving current in the CC state. The aforementioned three CC control methods can be compared and are listed in Table 1.

The transfer function (TF) of the duty cycle to the SBBC output current for the buck or boost operation can refer to studies [20,21]; both models have been derived based on a PWM switch model technology from previous studies $[16,22,23]$. Therefore, the SBBC transfer function is defined as follows:

$$
G_{k t}(s)=\widetilde{i_{0}} / \widetilde{d}=k_{c o n}\left(n u_{2} s^{2}+n u_{1} s+n u_{0}\right) /\left(d e_{2} s^{2}+d e_{1} s+d e_{0}\right) .
$$

According to the buck or boost operation of SBBC, these parameters in (11) are listed in Table 2. In Table 2, $r_{c}$ represents the capacitor's ESR. $r_{L}$ represents the inductor's wire-wind resistance. $r_{\text {hpld }}$ represents the HPLDs' equivalent dynamic resistor, which can be calculated as:

$$
r_{h p l d}=3\left(V_{L D 2}-V_{L D 1}\right) /\left(I_{L D 2}-I_{L D 1}\right),
$$

where $V_{L D 1}$ and $V_{L D 2}$ are HPLDs' operating forward voltages, and $I_{L D 1}$ and $I_{L D 2}$ are HPLDs' operating forward currents. 


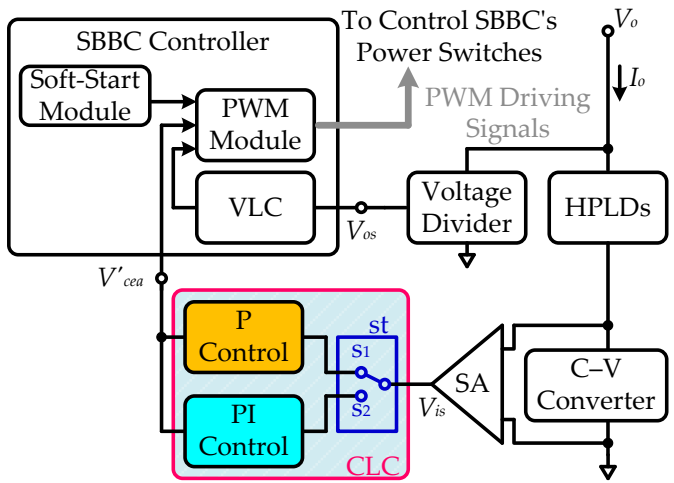

(a)

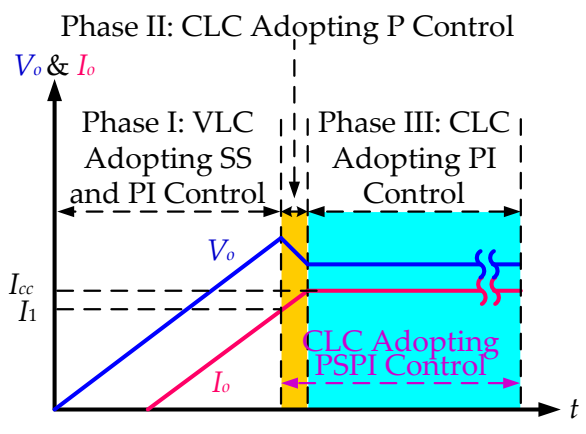

(b)

Figure 9. Current-loop controller (CLC) using proportional-integral associating proportional (PIAP) control: (a) Circuit configuration diagram; (b) start-up phase principle.

Table 1. Three constant-current (CC) control methods.

\begin{tabular}{cccc}
\hline CC Control Technology & $\begin{array}{c}\text { Driver Output } \\
\text { Mode }\end{array}$ & $\begin{array}{c}\text { Driving Current } \\
\text { Compensation }\end{array}$ & $\begin{array}{c}\text { Start-up Current } \\
\text { Spike Mitigation }\end{array}$ \\
\hline CC Sink & CVOM & N/A & N/A \\
\hline $\begin{array}{c}\text { CC Source Using } \\
\text { Proportional-Integral (PI) Control }\end{array}$ & CVOM \& CCOM & PI compensation & N/A \\
\hline $\begin{array}{c}\text { CC Source Using } \\
\begin{array}{c}\text { Proportional-Integral Associating } \\
\text { Proportional (PIAP) Control }\end{array}\end{array}$ & CVOM \& CCOM & P and PI compensations & Effectual \\
\hline
\end{tabular}

Table 2. Parameters in Equation (11).

\begin{tabular}{ccc}
\hline Notation & Transfer Function (TF) Parameter for Buck Mode & TF Parameter for Boost Mode \\
\hline$n u_{2}$ & 0 & $-L_{1} r_{c} / r_{h p l d}$ \\
$n u_{1}$ & $r_{c} C_{o}$ & $r_{c}\left(1-D_{b t}\right)^{2}-L_{1} /\left(r_{h p l d} C_{o}\right)-r_{c} r_{L} / r_{h p l d}$ \\
$n u_{0}$ & 1 & $-r_{L} /\left(r_{h p l d} C_{o}\right)+\left(1-D_{b t}\right)^{2} / C_{o}$ \\
$d e_{2}$ & $\left(L_{1} C_{o}\right)\left(r_{h p l d}+r_{c}\right) /\left(r_{h p l d}+r_{L}\right)$ & $L_{1}\left(r_{c} / r_{h p l d}+1\right)$ \\
$d e_{1}$ & $C_{o} r_{c}+r_{h p l d} r_{L} /\left(r_{h p l d}+r_{L}\right)+L_{1} /\left(r_{h p l d}+r_{L}\right)$ & $r_{c}\left(1-D_{b t}\right)^{2}+r_{L}+r_{c} r_{L} / r_{h p l d}+L_{1} /\left(r_{h p l d} C_{o}\right)$ \\
$d e_{0}$ & 1 & $r_{L} /\left(r_{h p l d} C_{o}\right)+\left(1-D_{b t}\right)^{2} / C_{o}$ \\
$k_{\text {con }}$ & $V_{\text {in (max) }} /\left[r_{h p l d}\left(r_{h p l d}+r_{L}\right)\right]$ & $V_{o} /\left[r_{h p l d}\left(1-D_{b t}\right)\right]$ \\
\hline
\end{tabular}

The current-loop control block diagram of FSBBC is illustrated in Figure 10. In Figure 10, the FSBBC gain is $G_{k t}$, the FSBBC controller gain is $G_{c t l r}$, the CLC gain using the P control is $G_{c e a(P)}$, the CLC gain using the PI control is $G_{c e a(P I)}$, and a feedback gain is a constant, $k_{c}$. In addition, the soft-start function would affect the start-up current spike, hence, it should be considered; $G_{s S}$ represents the soft-start control gain.

Despite whether the SBBC controller implements the buck or boost control, a linear polynomial of the $d-v_{c e a}$ characteristic is expressed as follows:

$$
d=k_{c e a} v_{c e a}+r
$$

where $d$ is the PWM duty cycle that incorporates the large-signal, $D$, with the small-signal, $\widetilde{d} . v_{c e a}^{\prime}$ is the CLC output voltage that incorporates the large-signal, $V_{c e a}^{\prime}$, with the small-signal, $\widetilde{v}_{c e a}^{\prime}$. Both $k_{c e a}$ and $r$ are constants. Substitution of $d=D+\widetilde{d}$ and $v_{c e a}^{\prime}=V_{c e a}^{\prime}+\widetilde{v}_{c e a}^{\prime}$ into Equation (13), results in the SBBC controller TF being expressed as follows: 


$$
G_{c t l r}(s)=\widetilde{d} / \widetilde{v}_{c e a}=k_{c e a} .
$$

The $v_{c e a}$ can exponentially increase in the start-up transient phase to accomplish the soft-start control for the CLC output voltage, $v_{c e a}^{\prime}$; hence, the TF of the soft-start control can be expressed as follows:

$$
G_{s s}(s)=\widetilde{v}_{c e a} / \widetilde{v}_{c e a}^{\prime}=1000 /(s+1000) .
$$

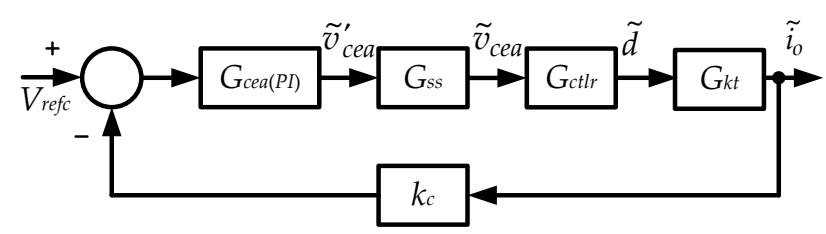

(a)

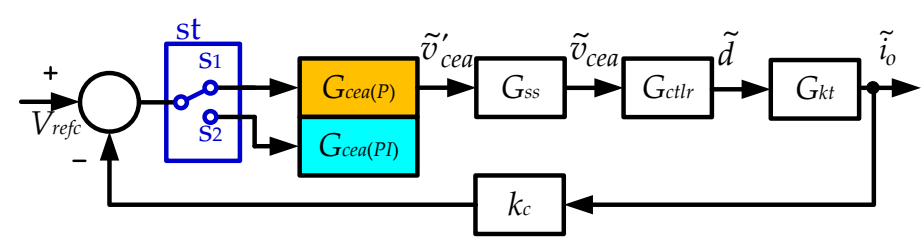

(b)

Figure 10. Control block diagram of CLC: (a) Proportional-integral (PI) control; (b) PIAP control.

From Figure 10, open-loop TFs $G_{o p(b t)}(s)$ and $G_{o p(b k)}(s)$ can be obtained using (11) and (14), which can be expressed as follows:

$$
\begin{gathered}
G_{o p(b t)}(s)=G_{c t l r(b t)}(s) G_{k t(b t)}(s), \\
G_{o p(b k)}(s)=G_{c t l r(b k)}(s) G_{k t(b k)}(s),
\end{gathered}
$$

where $G_{k t(b t)}(s)$ and $G_{c t l r(b t)}(s)$ are the SBBC TF and SBBC controller in the boost mode operation. $G_{k t(b k)}(s)$ and $G_{c t l r(b k)}(s)$ are in the buck mode operation.

By substituting Equations (16) and (17), and using the MATLAB software, the frequency response to design the CLC for the current loop compensation of HPLDDC can be obtained. Therefore, the HPLDDC requirements for the steady-state operation, including an adequate phase margin, a high low-frequency gain (LFG), and a feasible crossover frequency, can be achieved. The TF of the CLC using the PI control is expressed as follows:

$$
G_{c e a(P I),}(s)=g_{p}\left(s+g_{i} / g_{p}\right) / s=g_{p}+g_{i} / s
$$

where $g_{i}$ and $g_{p}$ are the integral and proportional gains.

\section{Design Consideration and Simulation}

In this study, the PL TB405B is the HPLD type-number (Osram Opto Semiconductors Inc., Regensburg, Germany). Its specification is listed in Table 3 from the datasheet [12].

As shown in Figure 2, at the HPLDDC input side, the minimum input voltage, $V_{\text {in }(\min ) \text {, and the }}$ maximum input voltage, $V_{\text {in }(\max )}$, from the on-board batter were set as 9 and $16 \mathrm{~V}$; at the HPLDDC output side, three blue-beam HPLDs were series connections, and the HPLD's forward voltage was 14.4 $\mathrm{V}$ from $V_{L D 2}$ in Table 3. Hence, the minimum output voltage of HPLDDC $V_{o(\min )}$ was set as $13 \mathrm{~V}$, and the maximum output voltage of HPLDDC $V_{o(\max )}$ was set as $16 \mathrm{~V}$. The HPLDDC output current, $I_{0}$, was $1.2 \mathrm{~A}$ for the CC operation. In addition, the switching frequency of $Q_{1}-Q_{4}$ (Figure 3) $f_{s}$ 
was $400 \mathrm{kHz}$. $\alpha$ was set as $1 \%$, and $\beta$ was set as $20 \%$. These parameters and specifications are listed in Table 4.

Table 3. Specification of high-power laser diode (HPLD) at $25^{\circ} \mathrm{C}$.

\begin{tabular}{cc}
\hline Depiction & Specification \\
\hline $\begin{array}{c}\text { Operating forward voltage }\left(V_{L D 1}\right) \\
\text { at the operating forward current } I_{L D 1}=0.9 \mathrm{~A}\end{array}$ & $4.7 \mathrm{~V}$ \\
\hline $\begin{array}{c}\text { Operating forward voltage }\left(V_{L D 2}\right) \\
\text { at the operating forward current } I_{L D 2}=1.2 \mathrm{~A}\end{array}$ & $4.8 \mathrm{~V}$ \\
\hline Optical output power & $1.6 \mathrm{~W}$ \\
Maximum operating current & $1.5 \mathrm{~A}$ \\
Laser emission wavelength & $450 \mathrm{~nm}$ \\
Operating temperature range & $-40{ }^{\circ} \mathrm{C}$ to $85{ }^{\circ} \mathrm{C}$ \\
Package & TO56 \\
\hline
\end{tabular}

Table 4. High-power laser diode driving controller (HPLDDC) parameters and specifications.

\begin{tabular}{cccc}
\hline Parameter & Specification & Parameter & Specification \\
\hline$V_{\text {in (min })}$ & $9 \mathrm{~V}$ & $V_{\text {in }(\max )}$ & $16 \mathrm{~V}$ \\
$V_{O(\min )}$ & $13 \mathrm{~V}$ & $V_{o(\max )}$ & $16 \mathrm{~V}$ \\
$I_{O}$ & $1.2 \mathrm{~A}$ & $f_{S}$ & $400 \mathrm{kHz}$ \\
$\alpha$ & $1 \%$ & $\beta$ & $20 \%$ \\
\hline
\end{tabular}

The power converter topology was the SBBC, which could be operated in both buck and boost conversion modes, when variable battery voltages input to the HPLDDC. In different input and output voltages, the SBBC operating mode can be changed by the SBBC controller. To ensure the estimating inductor and output capacitor can address the buck and boost operating modes in practical applications, this study provides the design considerations and calculating rule to obtain the single element value for the SBBC circuit assembly.

\subsection{Inductor Value Calculation}

From Table 4, substitution of $V_{o(\min )}=13 \mathrm{~V}, V_{\text {in }(\max )}=16 \mathrm{~V}, f_{\mathrm{S}}=400 \mathrm{kHz}, \beta=20 \%$, and $I_{o}=1.2 \mathrm{~A}$ into (2) can obtain $L_{b k}=9.1 \mu \mathrm{H}$. In addition, substitution of $V_{o(\max )}=16 \mathrm{~V}, V_{\text {in (min) }}=9 \mathrm{~V}, f_{s}=400 \mathrm{kHz}$, $I_{o}=1.2 \mathrm{~A}$, and $\beta=20 \%$ into (4) can obtain $L_{b t}=20.5 \mu \mathrm{H}$.

\subsection{Output Capacitor Value Calculation}

From Table 4, substitution of $I_{o}=1.2 \mathrm{~A}, V_{\text {in }(\max )}=16 \mathrm{~V}, \alpha=1 \%$, and $f_{s}=400 \mathrm{kHz}$ into (7) can obtain $C_{o b k}=9.4 \mu \mathrm{F}$; in addition, substitution of the aforementioned parameters and $\beta=20 \%$ into (8) can obtain $E S R_{b k} \leq 109 \mathrm{~m} \Omega$. Moreover, substitution of $I_{o}=1.2 \mathrm{~A}, V_{\text {in }(\min )}=9 \mathrm{~V}, V_{o(\max )}=16 \mathrm{~V}, \alpha=1 \%$, and $f_{s}=400 \mathrm{kHz}$ into (9) can obtain $C_{o b t}=4.1 \mu \mathrm{F}$. Substitution of the aforementioned parameters and $\beta=20 \%$ into (10) can obtain $E S R_{b t} \leq 62 \mathrm{~m} \Omega$. These calculating values, including $L_{b k}, C_{o b k}, E S R_{b k}$, $L_{b t}, C_{o b t}$, and $E S R_{b t}$, are listed in Table 5. Circuit element specifications in Figures 2 and 9 are listed in Table 6.

Table 5. Calculating inductance and output capacitance values.

\begin{tabular}{cccc}
\hline Notation & Calculating Value & Notation & Calculating Value \\
\hline$L_{b k}$ & $9.1 \mu \mathrm{H}$ & $L_{b t}$ & $20.5 \mu \mathrm{H}$ \\
$C_{o b k}$ & $9.4 \mu \mathrm{F}$ & $C_{o b t}$ & $4.1 \mu \mathrm{F}$ \\
$E S R_{b k}$ & $109 \mathrm{~m} \Omega$ & $E S R_{b t}$ & $62 \mathrm{~m} \Omega$ \\
\hline
\end{tabular}


Table 6. Circuit element specification.

\begin{tabular}{|c|c|c|}
\hline Circuit Element & Type-Number & Specification \\
\hline$Q_{1}, Q_{2}, Q_{3}, Q_{4}$ & IRF7478PBF & $\begin{array}{c}\text { Maximum drain-source voltage is } 60 \mathrm{~V} \\
\text { Drain-source turning on resistance is } 26 \mathrm{~m} \Omega \\
\text { Drain current is } 7 \text { A at } 25^{\circ} \mathrm{C}\end{array}$ \\
\hline$L_{1}$ & CS127060 & $\begin{array}{c}\text { Inductance value: } 30 \mu \mathrm{H} \\
\text { Material: Sendust }\end{array}$ \\
\hline Blue-beam HPLDs & EEU-FR1E471Y & $\begin{array}{c}\text { Inductance value: } 470 \mu \mathrm{F} \\
E S R \leq 41 \mathrm{~m} \Omega, \\
\text { Aluminum electrolytic capacitance } \\
\text { Semiconductor laser diode } \\
\text { Material: InGaN-base } \\
\text { Laser emission: Blue beam. } \\
\text { See the Table } 3\end{array}$ \\
\hline $\begin{array}{l}\text { Operational amplifier } \\
\text { of } \\
\text { SA and CLC }\end{array}$ & LM258ADR & $\begin{array}{c}\text { Range of DC power supply: } 3 \mathrm{~V} \text { to } 32 \\
\text { VOpen-loop differential voltage gain: } 100 \mathrm{~dB} \\
\text { Unity gain bandwidth: } 0.7 \mathrm{MHz} \\
\text { Operational amplifier, package: } \mathrm{SO} 8 \\
\text { Operating temperature: }-40^{\circ} \mathrm{C} \text { to } 85^{\circ} \mathrm{C} \text {. }\end{array}$ \\
\hline
\end{tabular}

\subsection{HPLDDC Current Loop Analysis and Simulation}

Parameter values of Table 2 are listed in Table 7. In Table 7, substitution of $V_{L D 1}, V_{L D 2}, I_{L D 1}$, and $I_{L D 2}$ from Table 3 into (12) can yield $r_{\text {hpld }}=0.99 \Omega$. From Table 4 , substation of $V_{o(\max )}=16 \mathrm{~V}$ and $V_{\text {in }(\min )}=9 \mathrm{~V}$ into the formula $\left(V_{o(\max )}-V_{\text {in }(\min )}\right) / V_{o(\max )}$ can yield $D_{b t}=0.437$.

Table 7. Parameter values of Table 2.

\begin{tabular}{cccc}
\hline Parameter & Value & Parameter & Value \\
\hline$r_{\mathcal{C}}$ & $41 \mathrm{~m} \Omega$ & $r_{L}$ & $68 \mathrm{~m} \Omega$ \\
$V_{\text {in (max })}$ & $16 \mathrm{~V}$ & $C_{o}$ & $470 \mu \mathrm{F}$ \\
$L_{1}$ & $30 \mu \mathrm{H}$ & $r_{\text {hpld }}$ & $0.99 \Omega$ \\
$D_{b t}$ & 0.437 & & \\
\hline
\end{tabular}

To yield the $d-v_{c e a}$ characteristic of SBBC in the boost mode, the testing conditions were defined as $V_{o(\max )}=16 \mathrm{~V}$ and $V_{\text {in (min })}=9 \mathrm{~V}$ and, and the SBBC output current, $I_{0}$, was adjusted from 0.5 to $1.2 \mathrm{~A}$; the measurement points are depicted in Figure 11a. In addition, the curve fitting function of MATLAB was used to obtain a linear polynomial, and the notation, $d$, was replaced with $d_{b t}$; hence, Equation (13) can be rewritten as follows:

$$
d_{b t}=0.1 v_{c e a}+0.35
$$

Similarly, to yield the $d-v_{c e a}$ characteristic of SBBC in the buck mode, the testing conditions were defined as $V_{o}=12 \mathrm{~V}$ and $V_{\text {in }}$ (max) $=16 \mathrm{~V}$, and the SBBC output current, $I_{o}$, was adjusted from 0.5 to $1.2 \mathrm{~A}$; the measurement points are depicted in Figure $11 \mathrm{~b}$. In addition, the curve fitting function of MATLAB was used to obtain a linear polynomial, and $d$ was replaced with $d_{b k}$; therefore, Equation (13) can be rewritten as follows:

$$
d_{b k}=0.23 v_{c e a}+0.64 \text {. }
$$

From Equation (14), $G_{c t l r}(s)=k_{c e a}$, and $k_{c e a}$ in the boost mode equals the constant 0.1 from Equation (19); hence, $G_{c t l r}(b t)(s)=0.1$. From Equation (20), in the buck mode, $G_{c t l r}(s)$ can be obtained and defined as $G_{c t l r(b k)}(s)=0.23$. 


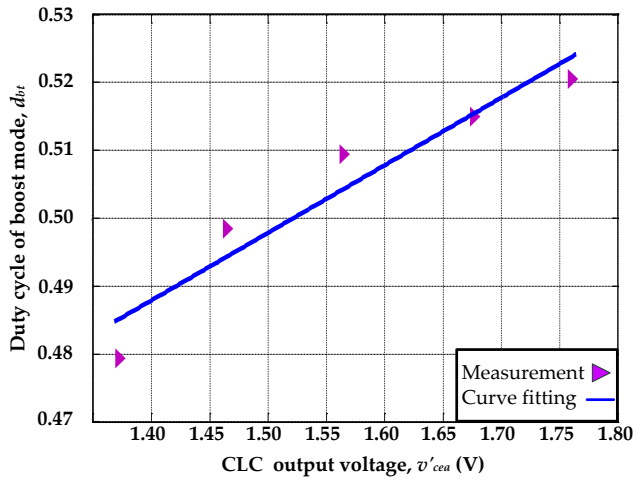

(a)

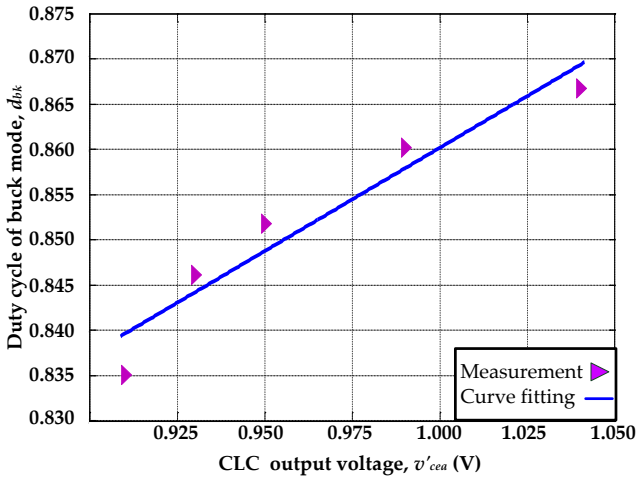

(b)

Figure 11. $d-v_{c e a}$ characteristics: (a) Boost mode; (b) buck mode.

Substitution of $G_{c t l r(b t)}(s)=0.1$ and $G_{c t l r(b k)}(s)=0.23$ into Equations (16) and (17), and using Matlab, frequency responses of buck and boost modes, are illustrated in Figure 12. From Figure 12, a resonant frequency point of $G_{o p(b t)}(s)$ was at $450 \mathrm{~Hz}$; hence, the compensative crossover frequency, $f_{c f}$, must be deviated from this resonant frequency point because the resonant occurrence would cause the HPLDDC instability. Moreover, $G_{o p(b k)}(s)$ bandwidth $(B W)$ was $7.7 \mathrm{~Hz}$, and it should be expanded for the HPLDDC response speed promotion. In addition, in the switching-mode DC-DC converters, $f_{c f}$ can be lower than the $f_{s} / 10$ [24]. According to these circumstances, $f_{c f}$ was $50 \mathrm{~Hz}$ for the HPLDDC operation.

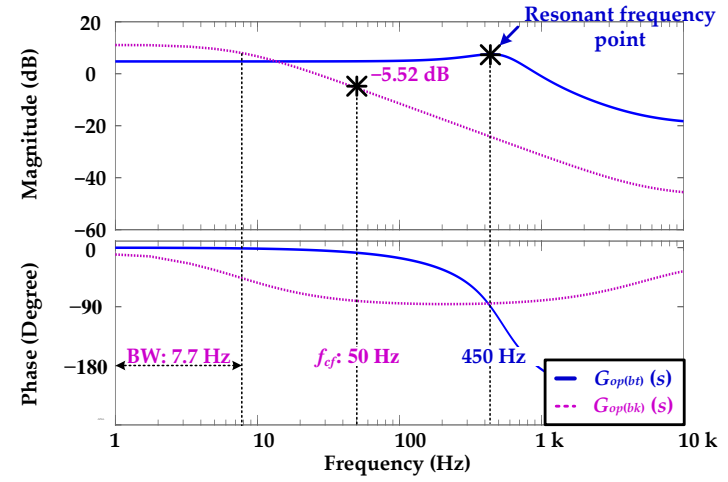

(a)

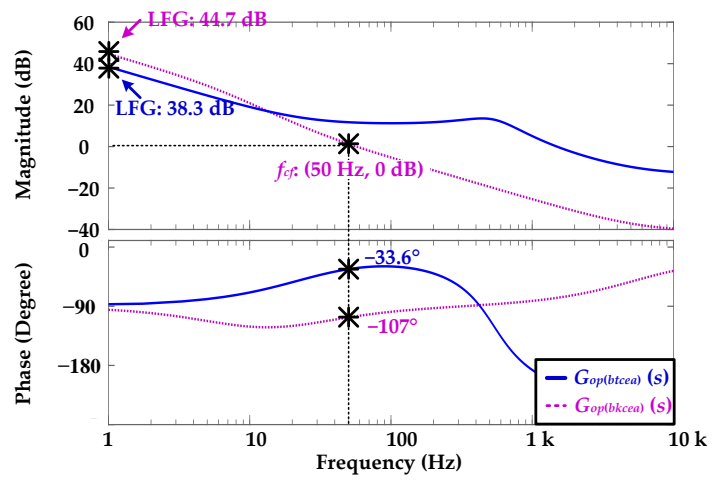

(b)

Figure 12. Open-loop frequency responses: (a) No PI control; (b) using PI control.

According to Figure 12, at $50 \mathrm{~Hz}, \mathrm{G}_{o p(b k)}$ should be promoted from -5.52 to $0 \mathrm{~dB}$. Therefore, the magnitude of Equation (18) can equal to a constant, $1.89(20 \log 1.89=5.52 \mathrm{~dB})$. Moreover, $g_{p}$ can be select as a suitable constant value. Hence, substitution of $g_{p}=2.2,\left|G_{c e a(P I)}\left[j\left(2 \pi f_{c f}\right)\right]\right|=1.89$ and $f_{c f}=50 \mathrm{~Hz}$ into Equation (18) can obtain $g_{i}=1.11 \times 10^{3}$.

Therefore, substitution of $g_{i}=1.11 \times 10^{3}$ and $g_{p}=2.2$ into Equation (18) can rewire $G_{c e a(P I)}(s)$, whose TF can be expressed as follows:

$$
G_{c e a(P I)}(s)=g_{p}+g_{i} / s=2.2+1.11 \times 10^{3} / s .
$$

In this study, the CLC TF using the PI control can adopt Equation (21). The CLC TF using the P control can employ the $g_{p}$ gain from Equation (18) that is given by:

$$
G_{c e a(P)}(s)=g_{p}=2.2 .
$$


In Figures 9 and $10, k_{c}$ is equal to $g_{s a} \times k_{c v}, g_{s a}$ is the SA's amplifier gain, $k_{c v}$ is the C-V converter gain. In this study, $g_{s a}$ and $k_{c v}$ were set as 16 and 0.05 , respectively; hence $k_{c}$ equaled to 0.8 . Moreover, an open-loop gain $G_{o p(b t c e a)}(s)$ equaled to $k_{c} \times G_{o p(b t)}(s) \times G_{c e a(P I)}(s)$. Therefore, use of the MATLAB could simulate the frequency response of $G_{o p(b t c e a)}(s)$, as shown in Figure 12b. From Figure 12b, the LFG was promoted to $38.3 \mathrm{~dB}$, and the phase was $-33.6^{\circ}$ at $50 \mathrm{~Hz}$. Furthermore, an open-loop gain, $G_{o p(b k c e a)}(s)$, equaled to $k_{c} \times G_{o p(b k)}(s) \times G_{c e a(P I)}(s)$. Hence, $G_{o p(b t c e a)}(s)$ simulation using the MATLAB is illustrated in Figure 12b. From Figure 12b, LFG was promoted to $44.7 \mathrm{~dB}$, and the phase was $-107^{\circ}$ at $50 \mathrm{~Hz}$. According to the frequency responses of $G_{o p(b t c e a)}(s)$ and $G_{o p(b k c e a)}(s)$, the HPLDDC using the designing CLC PI control can address the system stable requirement for buck and boost operations.

Incorporating $G_{o p(b t c e a)}(s)$ with $G_{s s}(s)$ of (15) and using Matlab, the simulation of HPLDDC start-up current for the boost mode is illustrated in Figure 13a. In addition, incorporating $G_{o p(b k c e a)}(s)$ with $G_{s s}(s)$ and using MATLAB, the simulation of the HPLDDC start-up current for the buck mode is illustrated in Figure 13b. Several situations can be observed in Figure 13:

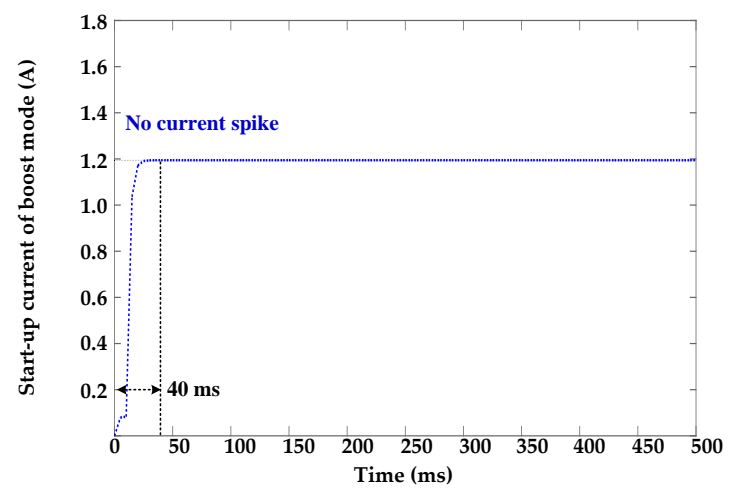

(a)

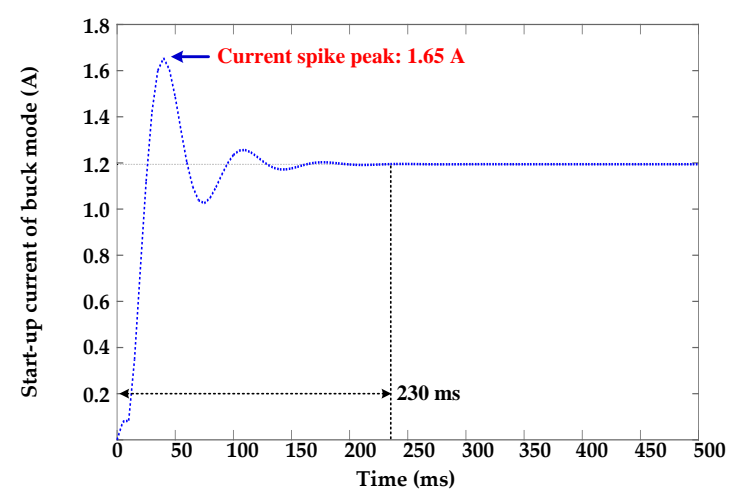

(b)

Figure 13. Simulations of CLC using PI control: (a) Boost mode; (b) buck mode.

1. Boost mode: No current spike occurred. The settling time was $40 \mathrm{~ms}$. The final current was $1.2 \mathrm{~A}$; and

2. Buck mode: Maximum start-up current peak was $1.65 \mathrm{~A}$. The settling time was $230 \mathrm{~ms}$. The final current was $1.2 \mathrm{~A}$.

From both figures, although the final current, 1.2 A, could correspond to the specification, a start-up current spike occurred in the buck mode operation. From these simulations, several disadvantages can be identified when the CLC uses the PI control. First, the peak current of $1.65 \mathrm{~A}$ already overstepped the specified 1.5 A, and this situation was harmful for HPLDs. Second, although the CLC using PI control had an outstanding ability to regulate steady-state errors, the PI control caused the start-up current spike when the SBBC operated in the buck mode.

To depress the start-up current spike, the CLC using the PIAP control method was employed. Simulations are presented in Figure 14. From Figure 14, despite the SBBC operating mode, the use of $\mathrm{P}$ control method cannot achieve the target final current of 1.2 A.

Thus, a CLC using the PIAP control method could be adopted in the HPLDDC. Figure 14 simulations show several benefits: First, the start-up current spike mitigated effectualness. Second, no steady-state errors were achieved, and the final current could address the specified 1.2 A because the HPLDDC using CLC can become the PI control in the SBBC CCOM. Third, the settling time was reduced from 230 to $80 \mathrm{~ms}$ in the SBBC buck mode. 


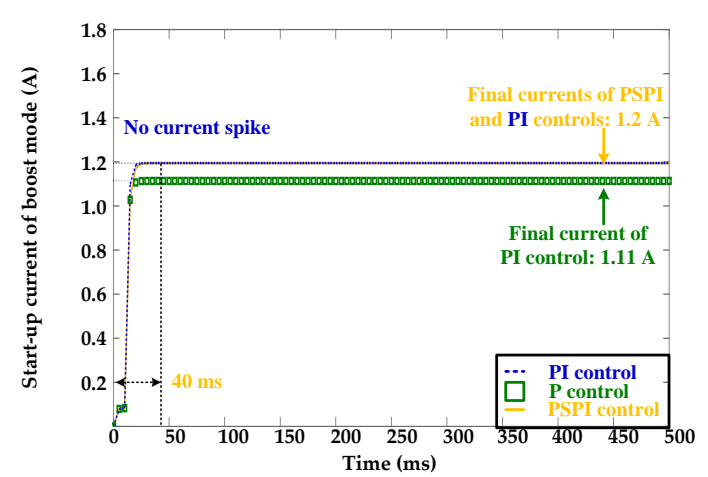

(a)

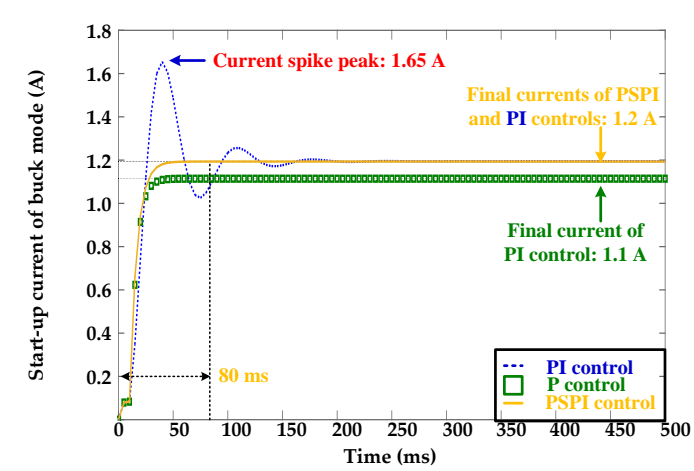

(b)

Figure 14. Simulations of CLC using PIAP control: (a) Boost mode; (b) buck mode.

\section{Experimental Results}

In accordance with the system configuration in Figure 2, the HPLDDC can drive the three blue-beam HPLDs. Figures 15 and 16 present the experimental waveforms, including the HPLDDC output current (HPLDs driving current), $I_{0}$, the HPLDDC input voltage, $V_{i n}$, and the HPLDDC output voltage (HPLDs driving voltage), $V_{o}$.

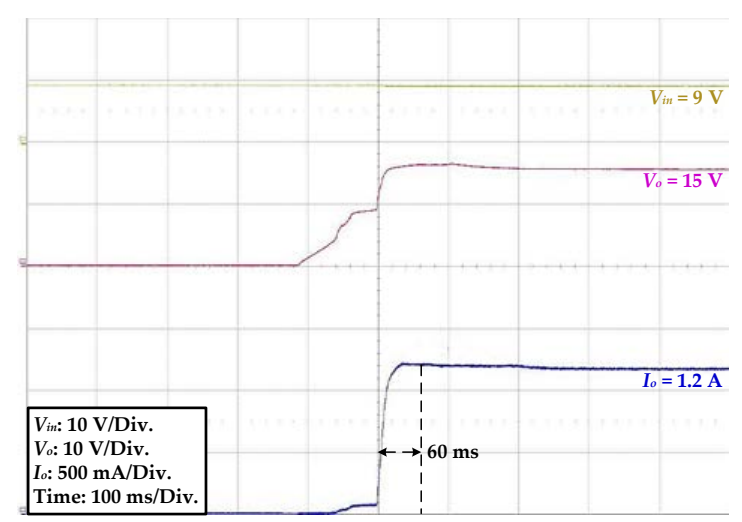

(a)

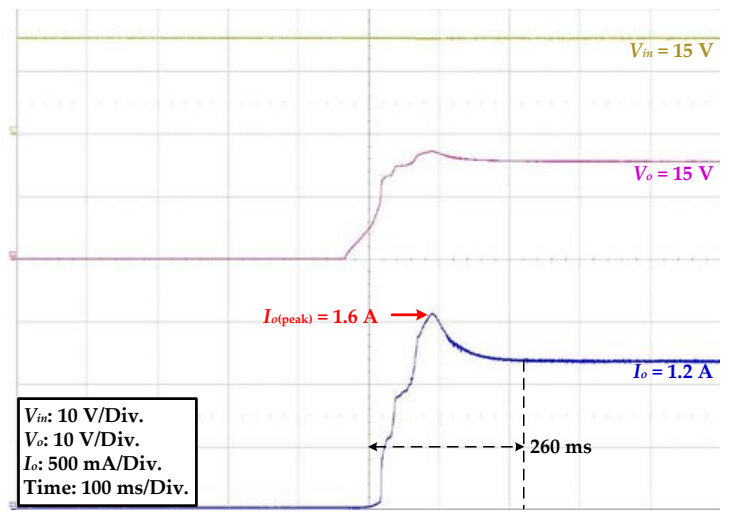

(b)

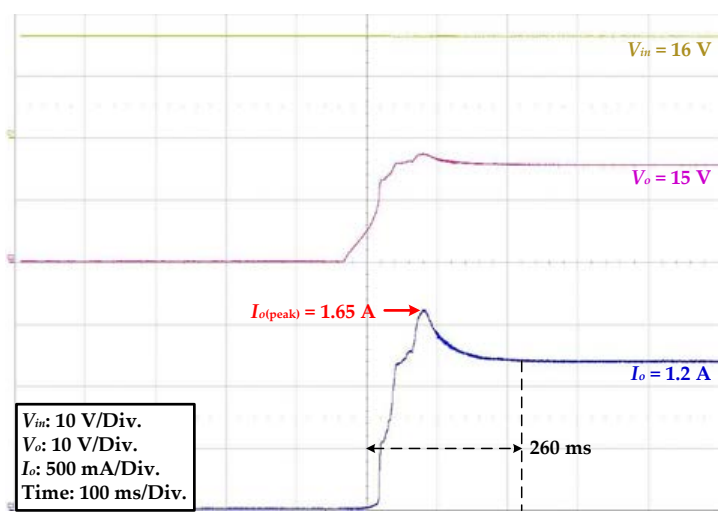

(c)

Figure 15. HPLDDC drove blue-beam HPLDs adopting PI control: (a) $V_{\text {in }}=9 \mathrm{~V}$ in boost operation; (b) $V_{\text {in }}=15 \mathrm{~V}$ in buck-boost operation; and (c) $V_{\text {in }}=16 \mathrm{~V}$ in buck operation. 


\subsection{CLC Using PI Control Method}

1. At a $V_{\text {in }}$ of $9 \mathrm{~V}$, the HPLDDC operated in the boost mode because $\left(V_{i n}=9 \mathrm{~V}\right)<\left(V_{o}=15 \mathrm{~V}\right)$, and a slight current spike was observed, with a peak value of $1.4 \mathrm{~A}$, and the settling time was $60 \mathrm{~ms}$ (simulation was $40 \mathrm{~ms}$ ), as shown in Figure 15a.

2. At a $V_{\text {in }}$ of $15 \mathrm{~V}$, the HPPLD operated in the buck-boost mode because $\left(V_{\text {in }}=15 \mathrm{~V}\right)=\left(V_{o}=15\right.$ $\mathrm{V})$, and the current spike was observed, with a peak was 1.6 A, which overstepped the HPLD maximum operating current of $1.5 \mathrm{~A}$ (Table 3). The settling time was $260 \mathrm{~ms}$, as shown in Figure $15 b$.

3. At a $V_{\text {in }}$ of $16 \mathrm{~V}$, the HPPLD operated in the buck mode because $\left(V_{\text {in }}=16 \mathrm{~V}\right)>\left(V_{o}=15 \mathrm{~V}\right)$, and the current spike was observed, with a peak was $1.65 \mathrm{~A}$. This peak value was also over the HPLD maximum operating current of $1.5 \mathrm{~A}$. Then, the settling time was $260 \mathrm{~ms}$ (simulation was $230 \mathrm{~ms}$ ), as shown in Figure 15c.

Thus, the start-up current spike must be mitigated, and it should be lower than the HPLD maximum operating current of $1.5 \mathrm{~A}$.

\subsection{CLC Using PIAP Control Method}

1. At a $V_{\text {in }}$ of $9 \mathrm{~V}$, the HPPLD operated the in the boost mode, and a slight current spike with a peak value of $1.25 \mathrm{~A}$ was observed. The settling time was $65 \mathrm{~ms}$ (simulation was $40 \mathrm{~ms}$ ), as shown in Figure 16a.

2. At a $V_{\text {in }}$ of $15 \mathrm{~V}$, the HPPLD operated in the buck-boost mode, a slight current spike was observed, with a peak of $1.3 \mathrm{~A}$, which was lower than the HPLD maximum operating current of $1.5 \mathrm{~A}$. The settling time was $100 \mathrm{~ms}$, as shown in Figure 16b.

3. At a $V_{\text {in }}$ of $16 \mathrm{~V}$, the HPPLD operated in the buck mode, and a slight current spike with a peak of $1.3 \mathrm{~A}$ was observed. This peak value was also lower than $1.5 \mathrm{~A}$. The settling time was $80 \mathrm{~ms}$ (simulation was $80 \mathrm{~ms}$ ), as shown in Figure 16c.

Therefore, the start-up current spike could be mitigated, and the current settling time could be obviously reduced, when the CLC used the PIAP control technology.

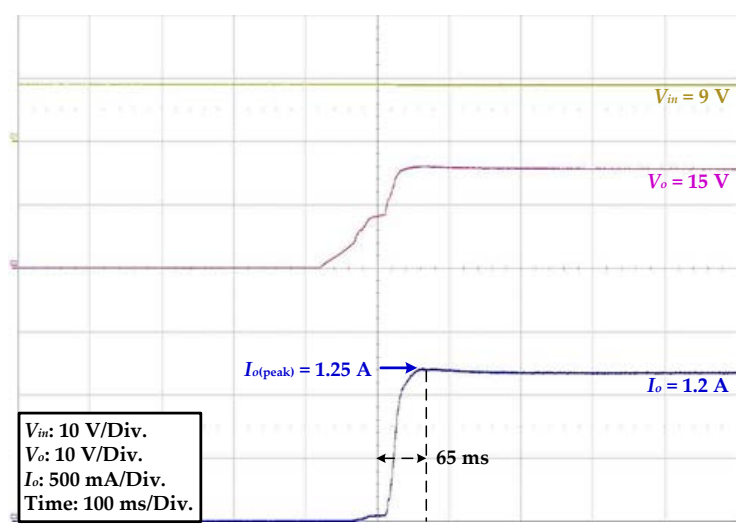

(a)

Figure 16. Cont. 


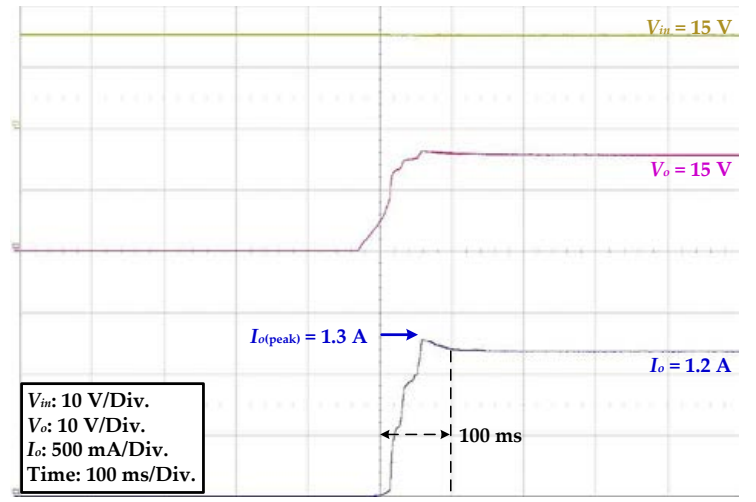

(b)

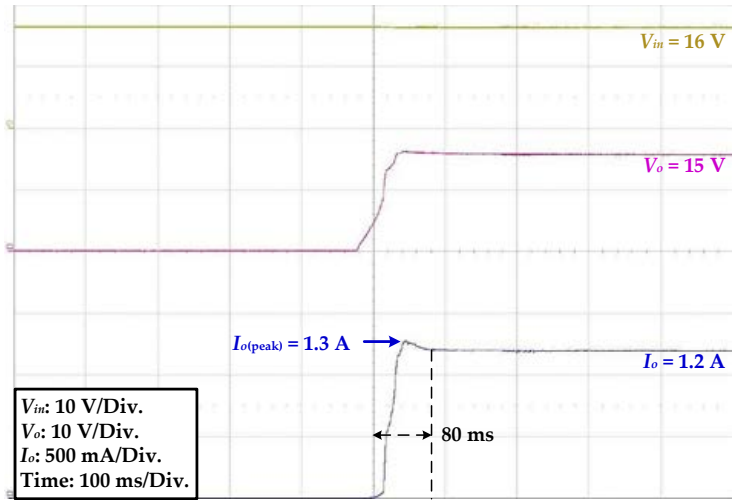

(c)

Figure 16. HPLDDC drove blue-beam HPLDs using PIAP control: (a) $V_{\text {in }}=9 \mathrm{~V}$ in boost operation; (b) $V_{\text {in }}=15 \mathrm{~V}$ in buck-boost operation; and (c) $V_{\text {in }}=16 \mathrm{~V}$ in buck operation.

A photograph of the HPLDDC system is presented in Figure 17, including three HPLDs' heat sinks, three heat-sink struts, a lead-acid battery, and a print circuit board assembly of the HPLDDC. The lead-acid battery could supply to the HPLDDC to drive HPLDs, and then laser blue beams were produced.

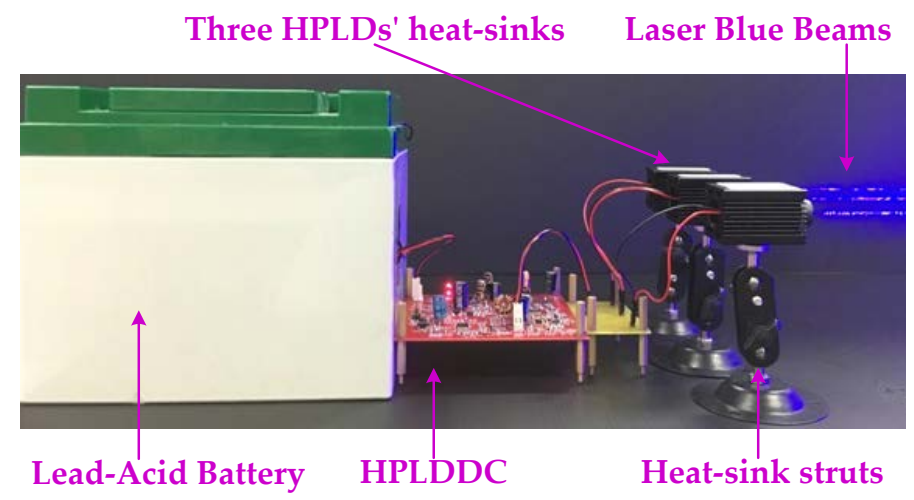

Figure 17. A photograph of the HPLDDC system.

\section{Conclusions}

This study developed and implemented an HPLDDC to drive three blue-beam HPLDs. An SBBC was employed as the power converter, which implemented the boost, buck, or buck-boost operation, to deal with the variable on-board battery voltages. In addition, the soft-start control was used to reduce the voltage spike in the start-up transient phase; however, this soft-start control method was incapable of handling the start-up current spike problem when the SBBC operated in the buck mode. Therefore, the proposed PIAP control technology could be applied in the CLC, which accomplished the following results: First, the PIAP control incorporated the P with the PI control to reduce the start-up current spike, and to abridge the settling time of the start-up current. Second, in the HPLDDC CCOM, the PIAP control can become the PI control to obtain the required stabilities, low steady-state errors, and sufficient phase margins. Third, the compensation parameters of the CLC were not required to be modified for the proposed PIAP control method. Finally, the CLC using the PIAP control technology was suitable in the current loop control of SBBC for accomplishing the HPLDDC CC operation.

Author Contributions: Conceptualization, K.-J.P. and C.-H.L.; Methodology, K.-J.P. and S.-Y.T.; Software, K.-J.P.; Validation, K.-J.P. and L.-D.Q.; Formal Analysis, K.-J.P.; Investigation, K.-J.P.; Writing-Original Draft Preparation, K.-J.P.; Writing-Review \& Editing, K.-J.P.; Supervision, K.-J.P.; Project Administration, K.-J.P. 
Funding: This research was funded by [the Ministry of Science and Technology, Taiwan (R.O.C.)]. The grant number [MOST 107-2221-E-131-008].

Acknowledgments: Authors acknowledge the Ministry of Science and Technology, Taiwan (R.O.C.) supplying a research fund.

Conflicts of Interest: The authors declare no conflict of interest.

\section{References}

1. Abu-Ageel, N.; Aslam, D. Laser-driven visible solid-state light source for etendue-limited applications. IEEE/OSA J. Disp. Technol. 2014, 10, 700-703. [CrossRef]

2. Longa, X.; Heb, J.; Zhouc, J.; Fangc, L.; Zhoub, X.; Renb, F.; Xu, T. A review on light-emitting diode based automotive headlamps. Renew. Sustain. Energy Rev. 2015, 41, 29-41. [CrossRef]

3. Ji, E.K.; Song, Y.H.; Lee, M.J.; Yoon, D.H. Thermally stable phosphor-in-glass for enhancement of characteristic in high power LED applications. Mater. Lett. 2015, 157, 89-92. [CrossRef]

4. Wu, H.; Zhang, X.; Ge, P. Modular design of a high-efficiency LED headlamp system based on freeform reflectors. Opt. Laser Technol. 2015, 72, 79-85. [CrossRef]

5. Aoike, N.; Hoshino, M.; Iwabuchi, A. Automotive HID headlamps producing compact electronic ballasts using power ICs. IEEE Ind. Appl. Mag. 2002, 8, 37-41. [CrossRef]

6. Chang, Y.N.; Cheng, H.L.; Chang, C.H.; Yen, H.C.; Lin, R.Z. An AC/DC LED driver with unity power factor and soft switching. Appl. Sci. 2018, 8, 780. [CrossRef]

7. Cheng, C.A.; Chang, E.C.; Tseng, C.H.; Chung, T.Y. A single-stage LED tube lamp driver with power-factor corrections and soft switching for energy-saving indoor lighting applications. Appl. Sci. 2017, 7, 115. [CrossRef]

8. Cheng, H.L.; Moo, C.S.; Yang, C.S.; Huang, C.K. Analysis and implementation of an HPF electronic ballast for HID lamps with LFSW voltage. IEEE Trans. Power Electron. 2012, 27, 4584-4593. [CrossRef]

9. Chiu, H.J.; Lo, Y.K.; Yao, C.J.; Cheng, S.J. Design and implementation of a photovoltaic high-intensity-discharge street lighting system. IEEE Trans. Power Electron. 2011, 26, 3464-3471. [CrossRef]

10. Keyence Corp. Laser Technical Guide; Keyence Corp.: Osaka, Japan, 2015.

11. USHIO Opto Semiconductors Inc. Chip Structure and Lasing Modes; USHIO Opto Semiconductors Inc.: Kyoto, Japan, 2014.

12. OSRAM Opto Semiconductors Inc. Using OSRAM OS Visible InGaN Laser Diodes; OSRAM Opto Semiconductors Inc.: Regensburg, Germany, 2013.

13. Seok, J.K.; Kim, K.T.; Lee, D.C. Automatic mode switching of P/PI speed control for industry servo drives using online spectrum analysis of torque command. IEEE Trans. Ind. Electron. 2007, 54, 2642-2647. [CrossRef]

14. Roberto, M.C.; Edmundo, B.H.; Marco, A.; Caporal, M. DSP-based digital torque/motion control of DC motors for direct-drive industrial robotic applications. In Proceedings of the 2010 IEEE Electronics, Robotics and Automotive Mechanics Conference, Morelos, Mexico, 28 September-1 October 2010; pp. 613-618.

15. Naouar, M.W.; Naassani, A.; Monmasson, E.; Slama-Belkhodja, I. FPGA-based speed control of synchronous machine using a P-PI controller. In Proceedings of the 2006 IEEE International Symposium on Industrial Electronics, Montreal, Canada, 9-13 July 2006; pp. 1527-1532.

16. Robert, E.W.; Maksimovic, D. Fundamental of Power Electronics, 2nd ed.; Kluwer Academic Publishers: Norwell, MA, USA, 2001; ISBN 0792372700.

17. Texas Instruments Inc. LM5118-Q1 Wide Voltage Range Buck-Boost Controller; Texas Instruments Inc.: Dallas, TX, USA, 2004.

18. Wu, C.Y.; Wu, T.F.; Tsai, J.R.; Chen, Y.M.; Chen, C.C. Multistring LED backlight driving system for LCD panels with color sequential display and area control. IEEE Trans. Ind. Electron. 2008, 55, 3791-3799.

19. Chiu, H.J.; Cheng, S.J. LED backlight driving system for large-scale LCD panels. IEEE Trans. Ind. Electron. 2007, 54, 2751-2760. [CrossRef]

20. Rogers, E. Understanding Buck Power Stages in Switch Mode Power Supplies: Application Report; Texas Instruments Inc.: Dallas, TX, USA, 1999.

21. Fronczak, K. Stability Analysis of Switched Dc-Dc Boost Converters for Integrated Circuits. Master's Thesis, Rochester Institute of Technology, Rochester, NY, USA, 1 August 2013. 
22. Vorperian, V. Simplified analysis of PWM converters using model of PWM switch part I: Continuous conduction mode. IEEE Trans. Aerosp. Electron. Syst. 1990, 26, 490-496. [CrossRef]

23. Vorperian, V. Simplified analysis of PWM converters using model of PWM switch. II. Discontinuous conduction mode. IEEE Trans. Aerosp. Electron. Syst. 1990, 26, 497-505. [CrossRef]

24. Zhang, H.J. Modeling and Loop Compensation Design of Switching Mode Power Supplies; Linear Tech. Corp.: Milpitas, CA, USA, 2015.

(c)

(C) 2018 by the authors. Licensee MDPI, Basel, Switzerland. This article is an open access article distributed under the terms and conditions of the Creative Commons Attribution (CC BY) license (http://creativecommons.org/licenses/by/4.0/). 